
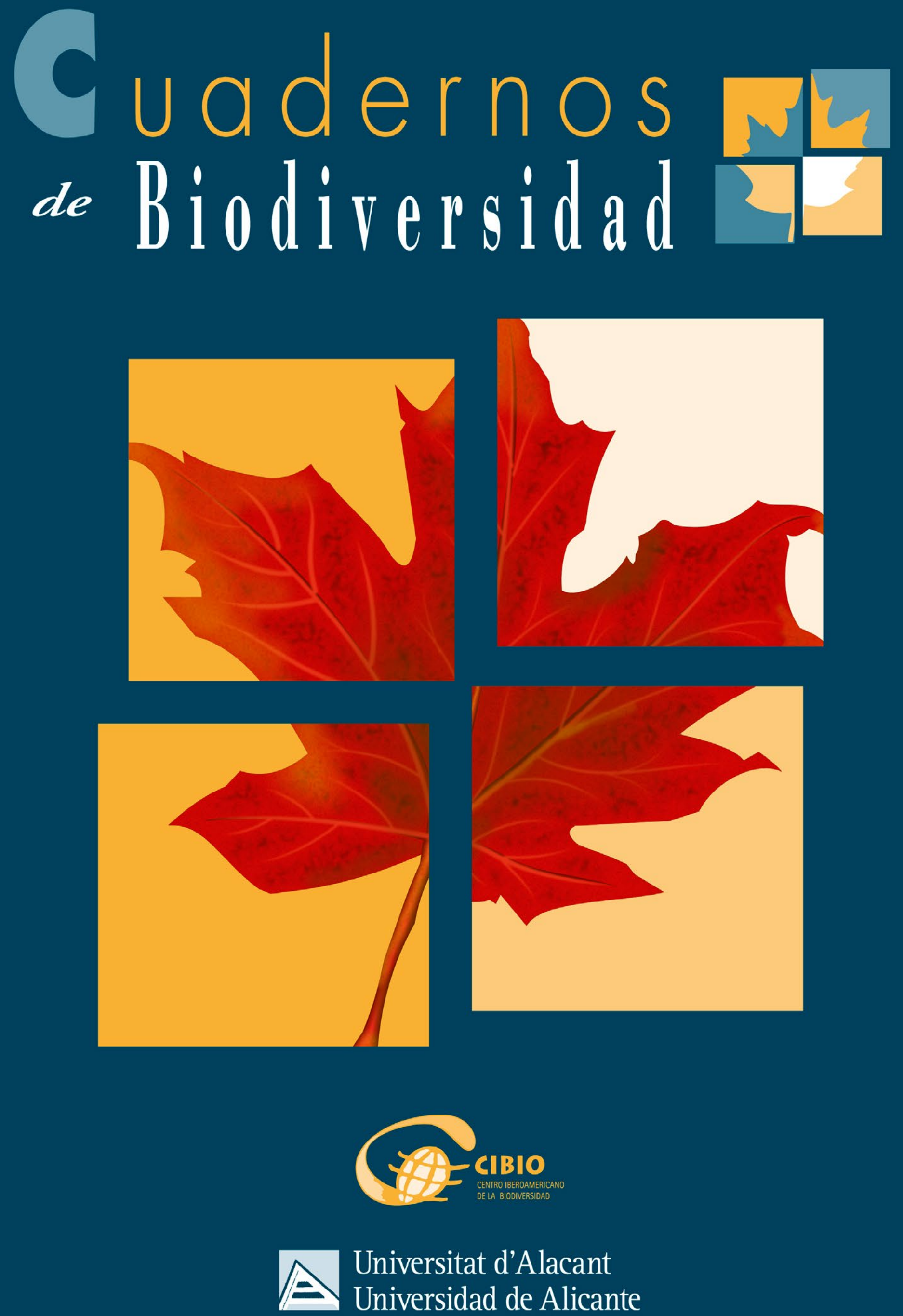


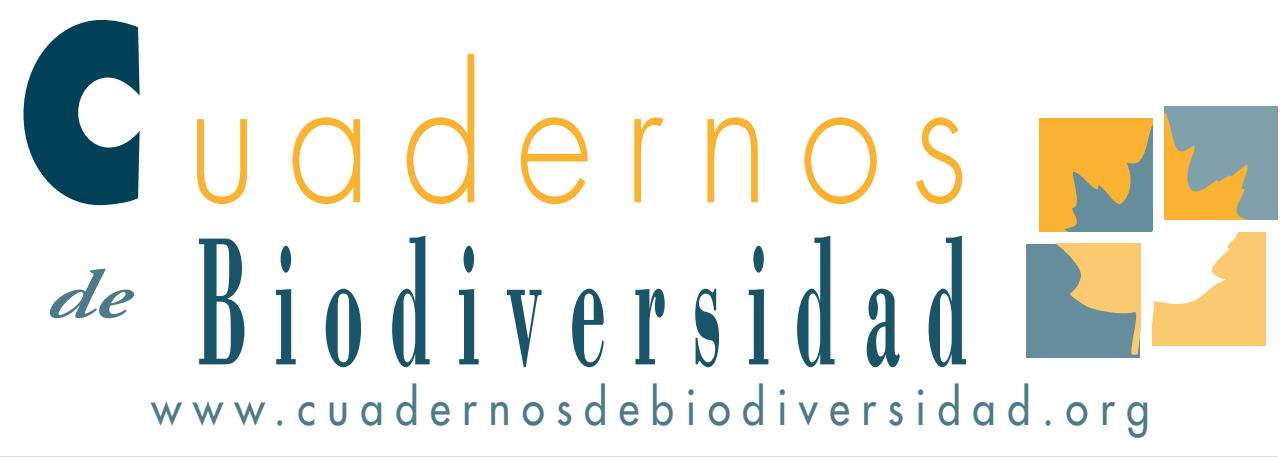

\section{¿Las plantas pueden revertir su sexo?}

\section{Iglesias-Andreu1* ${ }^{*}$ M. A. Baldo-Romero ${ }^{1}$ Y J.l. Casas- Martinez ${ }^{2}$}

I Instituto de Biotecnología y Ecología Aplicada (Inbioteca). Universidad Veracruzana Avenida de las Culturas Veracruzanas io i, Colonia Emiliano Zapata, C.P. 9iogo, Xalapa, Ver., México. Tel/Fax (228)842773.*Liglesias@Uv.mx

2 Centro Iberoamericano de la Biodiversidad (Cibio). Universidad de Alicante. Campus Universitario San Vicente del Raspeig, S/N. 03690 Alicante.

\section{ABSTRACT}

The sex determination is an event of great relevance in the life cycle of those plants that reproduce sexually. In recent years we have obtained substantial advances in elucidating the mechanisms involved, and in particular the role of epigenetic factors, in plant sex determination. Taking into account the relevance of this topic especially for dioecious species threatened as Cycads studies have been underwent to determine the basis of epigenetics of sex and to test whether compounds such as the de-metilating agent 5-azacytidine may be involved in sexual expression. This paper reviews the main progress made within this context obtained in $Z$. furfuraceae as well as cases of reversal of sex in cycads and different plant species.

Key words: Determination of sex, epigenetics, cycads, reversal of sex, 5-azaC.

\section{INTRODUCCIÓN}

Se ha descrito una extraordinaria diversidad en sistemas de determinación sexual en las plantas (Fig.1), que incluyen los sistemas Monomórficos (Hermafroditismo y Monoecia) y Dimórficos (Dioecia), así como los Polígamos monoicos (Andromonoica, Ginomonoica y Trimonoica) y los Polígamos dioicos (Androdioica, Ginodioica y Trioicas) (Ainsworth, 2000).

El conocimiento de los sistemas de determinación sexual en plantas está estrechamente ligado a la comprensión de cómo ha evolucionado la separación de los sexos. En algunas especies vegetales se ha detectado la presencia de cromosomas sexuales heteromórficos (Ainsworth, 2000) así como la presencia de genes que controlan el sexo como en Cucumis sativus (Pierce \& Wehner, 1990). Sin embargo, el control genético de la expresión sexual no parece 

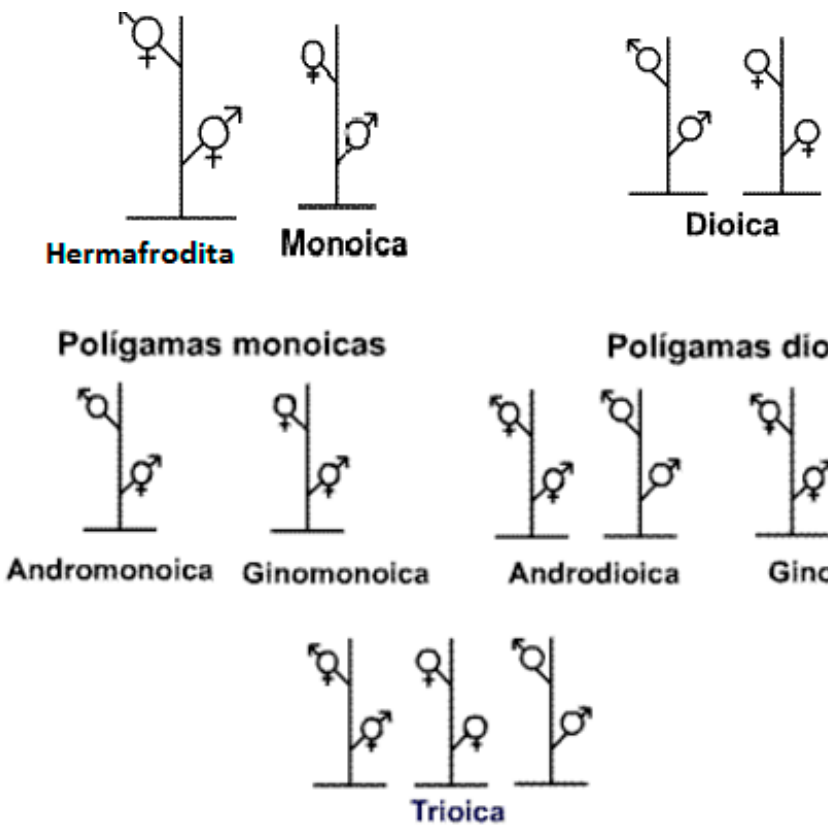

Poligamas dioicas

Figura 1. Representación gráfica de la diversidad de sistemas sexuales en el reino vegetal. (Fuente: Ainsworth, 2000).

ser suficientemente fuerte en todas las especies, para vencer los efectos y modificaciones de la expresión sexual por el ambiente (Lloyd, 1975). Por ello, la labilidad de los sistemas de determinación sexual en plantas puede deberse a la incapacidad que tienen los organismos de controlar de forma precisa el sexo en ambientes complejos o porque este le confiere una ventaja adaptativa (Korpelainen, 1998).

Aunque existen numerosos ejemplos de reversión del sexo en el reino animal, principalmente en peces y reptiles (Rud et al., 2015, Holleley et al., 2015), por factores ambientales, no abundan los casos que evidencian su efecto en la expresión del sexo de las plantas. Sin embargo se ha indicado que algunos factores ambientales, como sequía y temperatura, pueden modular su expresión y en ciertos casos ocasionar fenómenos de reversión sexual (Korpelainen, 1998). Ejemplo de ello se presenta en Thymelaea hirsuta. Esta especie muestra una expresión sexual lábil ya que los individuos pueden cambiar su sexo de año a año en respuesta a los cambios del ambiente (El-Keblawy et al., 1996). Bajo estos escenarios, un individuo diferenciado podría aumentar su aptitud (fitness), por un fenómeno de cambio de sexo o por un cambio en la proporción de los sexos, en respuesta a condiciones ambientales variables (Freeman \& Vitale, 1985). Sobre el particular, se ha indicado (Freeman et al., 1980) que cuando las condiciones ambientales son más limitantes las plantas se diferenciarán como machos, mientras que bajo condiciones favorables para la reproducción se promueve una mayor diferenciación de plantas hembras. Esto pudiera deberse a que las hembras requieren asignar más recursos durante su reproducción, que las plantas masculinas. Sin embargo esta respuesta puede llegar a variar con la especie y las condiciones ambientales. Un caso interesante fue observado por Nanami et al. (2016) en una población natural de Acer rufinerve en la que se observó un incremento del número de plantas femeninas, asociado con una reducción de los niveles de precipitación.

De igual forma se ha puesto de relieve el rol de las fitohormonas en la expresión sexual de las plantas (Korpelainen, 1998). Estudios recientes han permitido dilucidar los mecanismos mediante el cual estas hormonas interactúan y pueden actuar en la regula- 
ción de los genes del desarrollo floral, posiblemente a través de mecanismos de transducción de señales que modifican los niveles endógenos de algunas hormonas como auxinas y citoquininas (Golenberg \& West, 2013). El efecto hormonal sobre la expresión del sexo es dependiente de la especie. De hecho se ha indicado (Dellaporta \& Calderón-Urrea, 1993) que la misma hormona puede tener efectos totalmente opuestos en diferentes plantas. Por ejemplo, el ácido giberélico tiene un efecto feminizante en maíz, pero ejerce un efecto contrario en pepino. En algunas especies dioicas como Mecurialis annua la expresión del sexo es sensible a la aplicación exógena de hormonas, sin embargo en otras, como en Silene latifolia, su aplicación no parece tener un efecto sobre la expresión sexual (Dellaporta \& Calderón-Urrea, 1993). Las citocininas por otra parte pueden causar en Mercurialis annua, la conversión de individuos machos a hembras, pero puede tener un efecto contrario en otras especies. Aunque a nivel fisiológico, no se ha esclarecido bien la conexión entre la señalización hormonal y la sexualidad, la variación en las respuestas observadas, evidencia que cada especie debe poseer su propio mecanismo para la regulación hormonal del sexo.

En cicadas, Osborne y Gorelick (2007) describieron 33 casos de reversión sexual en 6 géneros y 17 especies, asociados a daños físicos o alteraciones severas ambientales. Según estos autores los cambios de sexo de macho a hembra están asociados a la exposición de las plantas a ambientes con baja luminosidad o a la exposición severa al frio, mientras que los cambios de género femenino a masculino parecen estar asociados con severa sequía (van Wyk \& Claassen, 1981, Osborne \& Gorelick, 2007). Los factores epigenéticos, además de los factores genéticos y fisiológicos, parecen estar involucrados en los mecanismos de determinación del sexo (Gorelick, 2005).

Como se sabe, la epigenética ha sido definida como los cambios heredables en la expresión génica que ocurren sin una alteración en la secuencia de nucleótidos del ADN. Así, un mecanismo epigenético puede ser entendido como un sistema complejo para utilizar selectivamente la información genética, activando y desactivando diversos genes funcionales. Aunque los mecanismos epigenéticos implicados en la determinación del sexo no han sido plenamente dilucidados, se ha resaltado el papel de la metilación diferencial de los cromosomas sexuales para explicar los diferentes patrones de determinación del sexo, cambio de sexo, dioecia y longitud diferente de los cromosomas sexuales (Gorelick, 2005). De acuerdo con este autor eventos como la metilación del ADN en dinucleótidos $\mathrm{CpG}$, constituye uno de los mecanismos epigenéticos que pueden estar implicados en la regulación de la expresión sexual en plantas. De hecho está bien establecido que la reprogramación epigenética consiste de cambios globales en la metilación del ADN y modificaciones en las histonas (Vyskot, 1999). Específicamente estos autores propusieron la hipótesis de que el sexo masculino debía contar con más loci regulatorios metilados que los genes que codifican la función femenina. De este modo ambos sexos podían tener diferentes patrones de grupos metilo en sus secuencias nucleotídicas.

Estos cambios pudieran deberse a eventos de reprogramación epigenética. Esta implicaría cambios globales en las modificaciones químicas a nivel de $\mathrm{ADN}$ y de histonas. Por ello para que se produzca correctamente la reprogramación tiene que producirse un reestablecimiento y reorganización del estado de su cromatina. Algunas marcas epigenéticas se perderán al mismo tiempo que se adquirirán las modificaciones que darán lugar a un nuevo estado.

Se considera que la metilación del ADN está implicada en la "memoria" de la célula somática y es crucial para mantener la integridad genómica. El papel de la metilación del $\mathrm{ADN}$ en relación a la expresión sexual de las plantas ha sido estudiado mediante el empleo del compuesto 5-azacitidina (5-azaC). Este compuesto es un análogo del nucleósido citidina que actúa como agente demetilante de las citosinas en las regiones hipermetiladas del ADN inhibiendo la acción del enzima ADN citosina c5-metiltranferasas, que fue sintetizado por primera vez por Piskala \& Sorm (1964). Li et al. (2015) constataron la existencia de un importante incremento en el porcentaje de individuos monoicos 
en espinaca (Spinacia oleracea L.) al ser sometido a este agente hipometilante. En Melandrium album (syn. Silene latifolia), se constató que la aplicación de tratamientos con 5-azaC permite lograr la conversión al androhermafroditismo en el 21\% de plantas masculinas (Janoušek et al., 1996), lo que muestra la capacidad de este compuesto en la determinación del sexo. Estos autores indicaron que los androhermafroditas bisexuales obtenidos (con el cariotipo masculino 24, AA + XY) presentaron flores hermafroditas y masculinas. Basado en los resultados obtenidos estos autores concluyeron que la supresión del sexo femenino en los machos XY de M. album depende de la metilación de secuencias específicas de ADN y puede ser heredablemente modificado por este agente hipometilante.

De particular interés resultan los resultados obtenidos en cicadas. En la búsqueda de estrategias para la conservación de Encephalartos woodii (Zamiaceae), cuyos únicos ejemplares disponibles corresponden a clones provenientes de un solo macho, Gorelick \& Osborne (2002) evaluaron el efecto de los compuestos $5 \mathrm{AzaC}$ y la variante 5 -aza-2'-deoxicitidina ( $5 \mathrm{AzadC}$ ) en vitroplántulas de esta especie a fin de inducir alteraciones en la metilación del $\mathrm{ADN}$ y con ello contribuir a la producción de plantas femeninas.
Esta estrategia se sustentaba en el supuesto de que si la diferenciación de los incipientes cromosomas sexuales presentes en esta especie es causada por una metilación diferencial entre machos y hembras, entonces un proceso de demetilación de la citosina, podría inducir el cambio de sexo. Partiendo de esta hipótesis el Instituto de Biotecnología y Ecología Aplicada (INBIOTECA) de la Universidad Veracruzana, ha venido desde hace años trabajando para evaluar el efecto de este agente hipometilante en la expresión sexual de la especie $Z$. furfuraceae (Fig. 2e). Para ello semillas de esta especie colectada en la población de "La Catalana" en Veracruz, México, fueron cultivadas en medio Murashige \& Skoog (1962) adicionado con diversas dosis (0, 400 y 600 $\mu \mathrm{M}$ ) del compuesto demetilante, 5AzaC (Fig. 2a). Las vitroplántulas tratadas (Fig.2b), fueron aclimatadas en condiciones de invernadero (Fig. 2c) y los juveniles (Fig. 2d) se están evaluando morfológica y molecularmente.

Estudios futuros permitirán dilucidar los mecanismos de determinación del sexo así como al manejo y conservación en este importante grupo de especies longevas, cuyas poblaciones naturales se encuentran en su mayoría amenazadas.

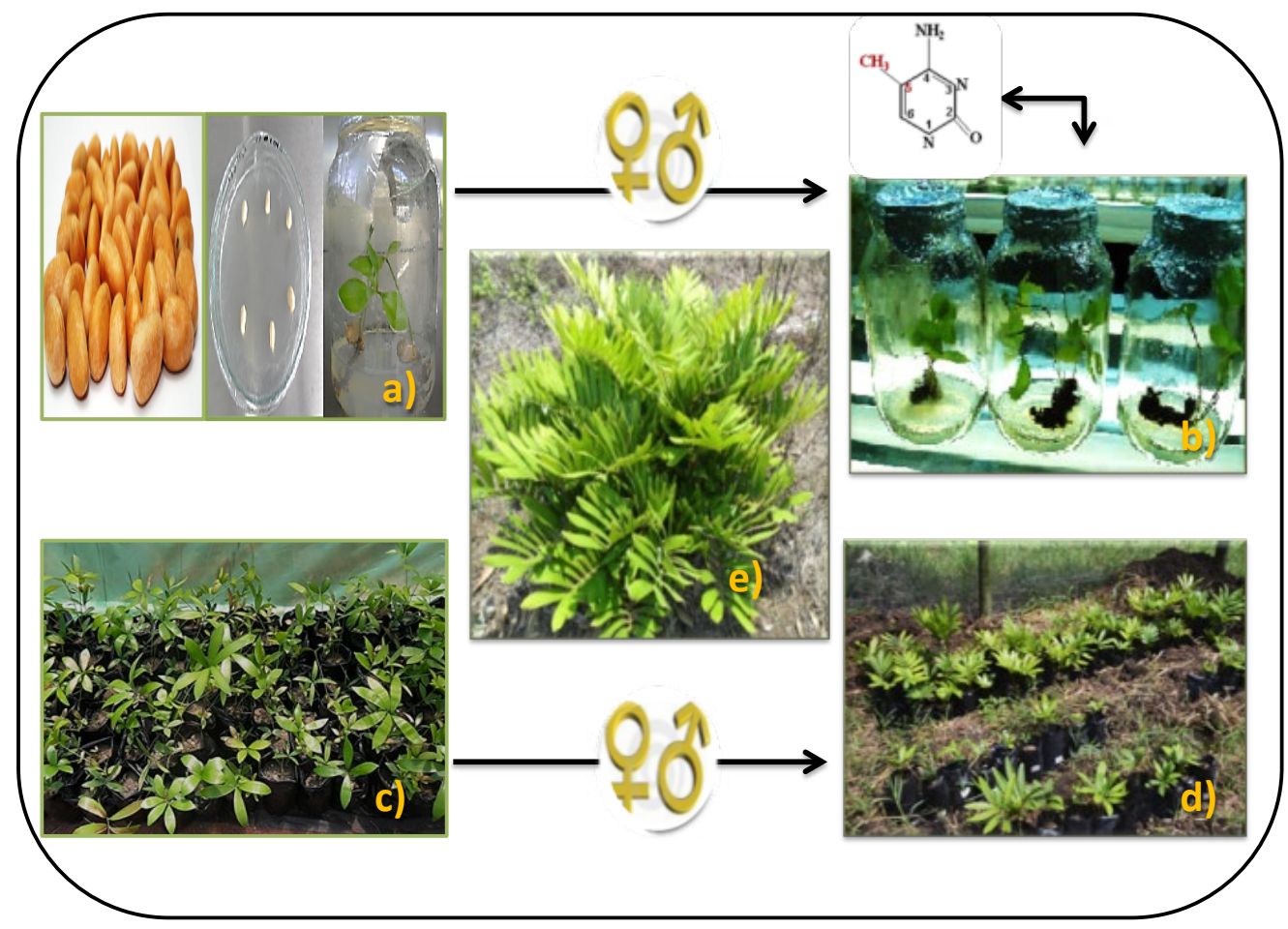

Figura 2. Plántulas de Z. furfuraceae sometidas a diferentes dosis de $5 \mathrm{azaC}$.

a) semillas colectadas y germinadas in vitro $b$ ) vitroplántulas tratadas con 5 aza C c) plántulas tratadas en fase de aclimatación d) plántulas juveniles tratadas e) individuo adulto de Z. furfuraceae 


\section{AGRADECIMIENTOS}

A CONACYT por la beca otorgada a la estudiante de Doctorado María Ángela Romero Baldo y por el apoyo financiero brindado al Proyecto de Ciencia Básica 152073.

\section{REFERENCIAS}

Ainsworth, C. 2000. Boys and girls come out to play: the molecular biology of dioecious plants. Annals of Botany. 86(2): 211-221.

Dellaporta, S.L. \& Calderón-Urrea, A. 1993. The sex determination process in maize. Science. 94: 1501. Doi. 10.1126/science.7985019.

El-Keblawy, A., Lovett Doust, J., Lovell Doust, L. \& Shaltout, K. 1996. Gender variation and the evolution of dioecy in Thymelae hisuita (Thymelaeaceae). Canadian Journal of Botany.74:1596-1601. Doi. 10.1139/b97-914.

Freeman, D.C., Harper, K.T. \& Charnov, E.L. 1980. Sex change in plants: old and new observations and new hypotheses. Oecologia. 47: 222-232. URL: http://www. jstor.org/stable/4216231.

Freeman, D.C. \& Vitale, J.J. 1985. The influence of environment on the sex ratio and fitness of spinach. Botanical Gazette. 146: 137-142. Doi. 10.1086/337508.

Golenberg, E.M. \& West, N.W. 2013. Hormonal interactions and gene regulation can link monoecy and environmental plasticity to the evolution of dioecy in plants. American Journal of Botany.100(6):1022-37. Doi: 10.3732/ajb.1200544

Gorelick, R. \& Osborne, R. 2002. Inducing sex change and organogenesis from tissue culture in the endangered African cycad Encephalartos woodii (Cycadales, Zamiaceae). South African Journal of Science. 98: 114-117.

Gorelick, R. 2005. Theory for why dioecious plants have equal length sex chromosomes. American Journal of Botany. 92: 979 - 984.

Holleley, C.E., O’Meally, D., Sarre, S.D., Marshall Graves, J.A., Ezaz, T., Matsubara, K., Azad, B., Zhang, X. \& Georges, A. 2015. Sex reversal triggers the rapid transition from genetic to temperature-dependent sex. Nature.523:79-82.
Janousek, B., Siroky, J. \& Vyskot, B. 1996. Epigenetic control of sexual phenotype in a dioecious plant, Melandrium album. Molecular and General Genetics. 250:483-490.

Korpelainen, H. 1998. Labile sex expression in plants. Biological Reviews of the Cambridge Philosophical Society. 73:157-180.

Li, S.F., Zhang, G.J., Yuan, J.H., Deng, C.L., Lu, L.D., Gao, W.J. 2015. Effect of 5-azaC on the growth, flowering time and sexual phenotype of spinach. Russian Journal of Plant Physiology. 62(5):670-675.

Lloyd, D.G.1975. Breeding systems in Cotula. III. Dioecious populations. New Phytology. 74: 109-123.

Murashige, T. \& Skoog, F. 1962. A revised medium for rapid growth and bioassays with tobacco tissue cultures. Physiology Plantarum. 15: 473-497.

Nanami, S., Kawaguchi, H. \& Yamakura, T. 2016. Sex Change towards Female in Dying Acer. Annals of Botany. 93(6):733-740.

Osborne, R. \& Gorelick, R. 2007. Sex Change in CycadsCases, Causes and Chemistry. Chapter 21. Reproductive Biology. Memoirs of the New York Botanical Garden. 97: 335-345.

Pierce, L.K. \& Wehner, T.C. 1990. Review of Genes and Linkage Groups in Cucumber. Hortscience. 25(6):60515. URL: http://hortsci.ashspublications.org/content/25/6/605.full.pdf

Piskala, A. \& Sorm, F. 1964. Collect Czech Chem. Commun. 29: 2060-2076. URL: http://dx.doi.org/10.1135/ cccc19642060-

Rud, Y.P., Maistrenko, M.I. \& Buchatskii, L.P. 2015. Sex identification of the rainbow trout Oncorhynchus mykiss by polymerase chain reaction. Russian Journal of Developmental Biology. 46(2): 65-70.

van Wyk, A.E. \& Claassen, M.I. 1981. Sex reversal in Encephalartos umbeluziensis. Veld and Flora. 67:120-122.

Vyskot, B. 1999. The role of DNA methylation in plant reproductive development in Sex Determination in Plants. (eds), C. C. Ainsworth: Sex Determination in Plants. BIOS Scientific Publishers Ltd, Oxford, United Kingdom. Chapter 6. pp. 101-120. 